\title{
Determinants of performance of Tunisia insurance companies: Case of life insurance
}

\author{
Abdelkader Derbali* \\ Higher Institute of Management of Sousse, University of Sousse, Tunisia \\ 22 Street Ahmed Hamza, Sahloul 1, Sousse 4054 Tunisia \\ E-mail: derbaliabdelkader@outlook.fr \\ *Corresponding author \\ Lamia Jamel \\ Faculty of Economic Sciences and Management of Sousse, \\ Department of Economics, Sousse University, Tunisia \\ Email: lajamel@yahoo.fr
}

\begin{abstract}
Business performance has attracted researchers' attention in the previous literature of corporate finance. However, in the framework of the life insurance sector, they have given a number of attentions. In our paper, we investigate empirically the effect of firm-specific characteristics (size, leverage, tangibility, risk, growth, liquidity and age) on the profitability of eight Tunisian insurance companies during the period of study from 2005 to 2015. The empirical results show that the variables size, age and growth are the most important determinants of the performance of Tunisian insurance companies as measured by Return on Asset ratio. Then, leverage, tangibility, liquidity and risk don't affect the performance of Tunisian insurance companies.
\end{abstract}

Keywords: Performance; life insurance; insurance companies; ROA; panel data

Biographical notes: Dr. Abdelkader Derbali is an Assistant Professor in Finance at the Higher Institute of Management of Sousse in University of Sousse, Tunisia. He is one of the Editorial Board Members in the Journal of Energy Markets, International Business Review, Cogent Economic \& Finance, International Review of Applied Economics, African Journal of Accounting, Auditing and Finance, and African Journal of Economic and Sustainable Development. His research interests include Risk Management, Systemic risk, International finance, Capital markets and institutions, Banking and market microstructure and Islamic Finance. He has published articles, among others, in Research in International Business and Management, Cogent Business \& Management, Cogent Economic \& Finance, Journal of Chinese Governance, The Chinese Economy, Journal of Energy Markets, African Journal of Accounting, Auditing and Finance, International Journal of Economics and Accounting, International Journal of Critical Accounting, and International Journal of Trade and Global Markets.

Dr. Lamia Jamel is a $\mathrm{PhD}$ in Economics at the Faculty of Economic Sciences and Management of Sousse, Tunisia. His research interests include Economic analysis, financial economics, quantitative finance, financial development, and energy commodities. She is one of the Editorial Board Members in the Cogent Economics and Finance, Journal of Chinese Governance, International Journal of Risk and Contingency Management, International Journal of Sustainable Economies Management, International Journal of Food and Beverage 
Manufacturing and Business Models, and International Journal of Managerial Studies and Research. She has published articles in African Journal of Accounting, Auditing and Finance and in Cogent Economic \& Finance. 


\section{Introduction}

Insurance companies make known significance for businesses and because individuals compensate losses and put them in positions where they were before they occur. In addition, insurers give economic, financial and social benefits for firms such as, loss prevention and diminution of anxiety.

However, it is true that investments are important for economic development and savings are the primary source of investments. Insurance company's products are the major instruments for the mobilization of savings of the families, particularly from middle and lower group households. Several research works have identified and analyzed the nexus among the role of insurance sector for stimulating the economic development by mitigating sudden and devastating occurrences (Horng et al., 2012; Lee et al., 2013; Yinusa and Akino, 2013; Taiwo et Al., 2014).

Insurance activities can be distinct as a service that provides a benefit upon the occurrence of a risk. Delivery, usually financial, may be for an individual, association or business in exchange for a perceived contributions or premiums. Thus, insurance activities are economic sector which includes the design, production and marketing of their services.

Given the quick expansion of financial markets, banks and insurance companies are in front of intense competition. Traditional performance measures come into sight to be insufficient to assemble the needs of strategic development of financial institutions (Zhang and Li, 2009).

The performance is an association between the functional efficiency and strategic effectiveness. Thus, functional performance is to improve the products, services, production processes and marketing and human resources management. Then, the strategic performance is ahead of the competition by positioning itself on a growing market (Chandler, 1992).

The problem of measuring the performance of insurance companies has been well developed in the literature of financial theory. Thus, the profitability of insurance companies can be influenced by external factors and internal factors (Demerguç-Kunt and Huizinga, 1999). In our study, we will examine the impact of specific features at the enterprise level on the performance of insurance companies in the case of life insurance. In this alignment, it begs the question: what are the main determinants of profitability of life insurance companies in Tunisia? 
To answer this question, we examine empirically the impact of firm-specific characteristics (size, leverage, tangibility, risk, growth, liquidity and age) on the profitability of eight Tunisian insurance companies during the period of study from 2005 to 2015. The empirical results show that the variables size, age and growth are the most important determinants of the performance of Tunisian insurance companies as measured by Return on Asset ratio. Then, leverage, tangibility, liquidity and risk don't influence the performance of Tunisian insurance companies.

The rest of the paper is organized as follow; in Section 2, we expose a review of related literature. In Section 3, we present the methodology and we illustrate the data employed for the empirical investigation. Section 4 finds the empirical findings and a discussion of the important results. Concluding remarks are showed in section 5. Section 6 presents the policy implications. Finally, in section 7, we found the suggestions for future researchs.

\section{Literature review}

In general, the majority of studies on bank performance have been established on samples of U.S. banks and some parts of some European banks such as; Angbazo (1997), Berger (1995), Neely and Wheelock (1997). For others banking systems of countries, the emphasis on a few studies in Colombia (Barajas et al., 1999), Brazil (Afanasieff et al., 2002), in Malaysia (Guru and Shanmugam, 2002) and in Tunisia (Ben Naceur and Goaied, 2001).

Determinants of performance have been widely studied in the literature of finance company in recent decades. In 1995, Berger conducts a survey on a sample of U.S. banks to determine the impact on the capital return on equity. He used in his study the ratio ROE (Return on Equity) to measure the performance of banks. He concluded that this ratio reveals the existence of a positive impact on the capital return on equity. The impact of the characteristics of banks in the United States on the net interest margin is examined. The results showed that the net interest margins of banks have a positive relationship with leverage, the opportunity cost, the risk of default and management efficiency (Ahmed et al., 2011; Angbazo, 1997).

Prakash et al. (2011) validate the multiple-item scale for measuring service quality in a way that it predicts customer satisfaction and patronage intentions in life insurance business in India. They utilize a structural equation modelling approach going after the model development strategy, which takes account of proposing a basic structural model framework 
and subsequently it improves the framework through modifications of competing structural models for arriving at the best-fit structural model. Their study has recognized that a satisfied life insurance customer is not necessarily a loyal one as the best-fit structural model does not include patronage intention. Based on the significant relationships observed in the best-fit structural model, content, welcome and alignment are identified as the main factors of service quality in life insurance business; and service quality has not been found to be leading to customer satisfaction significantly. This paper suffers from methodological limitations associated with convenience sampling and anonymous survey-based research.

Wahjudi et al. (2016) examine the impact of organisational culture on firm performance among Indonesia manufacturing firms. The empirical results from 152 organisations confirm that organisational culture has significant effect on firm performance. Only individualism and uncertainty avoidance significantly impact firm performance. Their implication is that, even in a country with many subcultures, firms' top management still need to pay attention to the impact of national culture at organisational level. In addition, since Indonesia has a very low score on individualism, managers need to create a conducive and rewarding environment for individuals to contribute.

George (2016) compares the productive efficiency and service quality of major foreign banks operating in India with that of the new private banks and also to study the linkages between efficiency, service quality and financial performance. George (2016) uses the data envelopment analysis (DEA) methodology for benchmarking of productive efficiency while SERVQUAL framework was used for service quality analysis. The linkages between productive efficiency, service quality and financial performance of a selected subset of both foreign and private banks were investigated. The empirical results of the analysis have clearly indicated that though both efficiency and service quality are extremely important they need not necessarily result in superior profitability of a bank. George (2016) contributes to the emerging need for a comprehensive framework for measuring efficiency, service quality and financial performance as well as their inter linkages for the Indian banks of different ownership structure.

Using data collected from 200 bank customers in two major cities in Klang Valley, Malaysia, Tan et al. (2016) investigate whether the five dimensions of SERVQUAL have an impact on customer satisfaction in Malaysian banking industry. They find out that the expectations of Malaysian banking customers are higher than perceptions in terms of service 
quality and tangible dimension has the largest influence on customer satisfaction. Their empirical findings provide several implications for bank management to improve upon their customer service quality in order to benefit from customer satisfaction which will lead to greater competitive advantage and profitability to the institutions concerned.

Sweis et al. (2016) examine the relationship between TQM practices and the organisational performance in the Jordanian courier service firms, and to determine which of the studied practices control the performance wheel. The methodology used is based on a cross sectional study carried out using a questionnaire survey. The survey is distributed to a sample of departments in a leading courier service firm in Jordan. Their empirical results show that TQM practices correlate positively with organisational performance, with a significant positive value for continuous improvement practice. Consequently, managers should consider TQM practices as a way to enhance performance, allocate resources and develop an environment that supports continuous improvement ideas.

This study aims to propose a conceptual framework to investigate the impact of organisational culture on quality practices and performance. Competing values framework has been used to capture the underlying value orientation of organisational culture and used the same to check its impact on performance. This study integrated both TQM and Six Sigma quality practices and defined a new set of infrastructure and core quality practices. In case of infrastructure practices, five practices have been identified which are top management support, customer relationship, supplier relationship, workforce management and Six Sigma role structure. Also, core practices resulted into five practices viz. quality information, product/service design, process management, Six Sigma focus on metrics and Six Sigma structured methodology. Further, a pilot study has been conducted in 40 medium scale manufacturing organisations to test the reliability of the constructs developed.

Kumar and Kumar (2016) present a real life example of improvement gained through implementation of VSM enabler of lean manufacturing. Their purpose is to discuss the measurable impact of lean manufacturing implementation on operational performance with the use of value stream mapping enabler of lean manufacturing.

In the study of Hosseini and Saravi-Moghadam (2016), to evaluate of brand equity dimension, the measuring tools suggested by different researcher, regarding local circumstances and Persian bank specifications, is used. The present research is a descriptive study by using a sample of 266 actual customers from seven branches in north provinces 
Saman bank of Iran. The findings in this paper support the five-dimensional model of customer-based brand equity in bank industry. The present study contributes to the understanding of customer-based brand equity measurement by examining the dimensionality of this construct. The paper shows that bank managers and executives should try to influence; perceived quality, brand loyalty, brand image, brand value and brand awareness in their organisations and design their service delivery process by considering relations between customer-based brand equity components.

In 1997, Ben Naceur and Goaied (2001) study the determinants of the profitability of commercial banks. They found that profitability is positively related to changes in the gross domestic product (GDP) per capita (Neely and Wheelock, 1997). In fact, other study relates to the measurement of the performance of Tunisian commercial banks. The empirical data used in this work were extracted from the database of the CBT (Central Bank of Tunisia). The sample included the largest commercial banks in Tunisia (10 banks) during the period 19802000.

In order to study the impact of bank characteristics, financial structure and macroeconomic indicators, net interest and performance of Tunisian banks for the period concerned margins.

It should be remembered that the different characteristics of banks account for a substantial part of the variation in net interest margin and the performance of the bank. The net interest margin and high performance tend to be associated with banks that hold a relatively large amount of capital.

Other determinants of bank performance on the net interest margin on bank loans have a positive and significant impact. Thus, the size has negative coefficient significance on net interest margins. This finding may simply reflect inefficiencies in the balance.

In addition, macro-economic indicators such as inflation and growth rates have no impact on net interest margins and bank profitability.

Finally, the financial structure has an impact on bank performance and the net interest margin. In fact, the concentration is less beneficial to commercial banks Tunisian competition. In addition, the stock market development has a positive effect on the performance of banks. This reflects the complementarities between bank performance and stock market growth, these complementarities is probably a factor of economic growth. Furthermore, the 
development of disintermediation of the Tunisian financial system supports the performance of the banking sector in particular and economic management.

The determinants of performance of Malaysian banks over the period of 10 years (19861995) are studied. At this point, they chose two features at the micro and macro level. The results showed that inflation and effective expenditure management have a negative impact on profitability, as the interest rate has a positive impact on profitability (Guru and Shanmugam, 2002).

Other authors developed a study of the determinants of profitability financial institutions. The results indicated that the credit risk and intensity loans are proportional inversely to profitability. Thus, financial institutions and large sizes that have a level of significant expenses tend to a high profitability ratio (Sufian, 2009).

But, in other studies we noted that liquidity, capital and investment are important determinants of bank profitability (Hakim and Neaime, 2005).

In addition, the growth of the money supply has a negligible effect on profitability, while GDP and the capitalization of assets on the stock market have a negative relationship with ROA (Return on Asset). Then, the profitability is positively affected by the size, sales growth and investment. On the other hand, current assets and leverage are negatively correlated with profitability. Several studies have been conducted to measure the performance of insurance companies. For example the functional status of insurers has no impact on the profitability to be provided by public coverage, but have a significant impact on the profitability of insurance companies. However, the size, the investment and the liquidity are the main determinants of the financial viability of insurance companies.

For the role of consolidation and deregulation in the insurance sector in Spain, we focuses on estimating the effect of EU directives on insurance (1994) and the policy of the Spanish Government in 1980 on changes in the market structure of the Spanish insurance. DemerguçKunt and Huizinga (1999) also determine that the consolidation has eliminated inefficient and poorly performing companies in the market. In the Spanish insurance sector, the role of organizational form is analyzed by comparing the stock and mutual insurers.

Then, other authors studied the impact of characteristics for insurance companies in Pakistan on the performance thereof. They selected a sample of five insurance companies for a period of seven years (2001-2007). In their study, the performance is expressed by the ratio 
of economic profitability (ROA) based on seven variables. They made an estimate by the method of OLS (Ordinary Least Square) to justify the most important determinants of the performance of insurance companies. These authors concluded that performance is positively influenced by the level of risk and the size of the firm. But this performance was negatively impacted by the debt ratio (leverage) (Sufian, 2009).

In addition, insurance companies must diversify their investment techniques and use an effective hedge for them to create adequate financial income. Since diversification minimizes the risk level.

\section{Research methodology}

\subsection{Sample}

Currently, there are nineteen insurance companies in Tunisia. According to the annual report (2015) published by the Tunisian Federation of insurance companies, we can show the increase generated by the insurance companies in Tunisia income. This report has enabled us to draw the following conclusions:

The premiums of the insurance sector totaled 1026.223 MD in 2015 against 961.921 MD in 2014, an increase of $6.68 \%$.

* The paid claims registered an increase of $18.69 \%$ from 505.709 MD in 2014 to 600.250 MD in 2015.

* Management fees totaled an amount of 181.415 MD in 2015 against 167.351 MD in 2014, an increase of $8.40 \%$.

* Technical reserves recorded an increase of 12.35\% in 2015 from 1820.791 MD and 2014 for 2045.696 MD in 2015.

* Investment amounts entered in balance sheet assets totaled 243.374 MD in 2015 against 205.227 MD in 2014, a growth rate of $11.88 \%$.

* The technical result for the year deteriorated in 2015, it recorded a surplus of 125.529 MD against 132.061 MD in 2014.

* The consolidated balance sheets were cleared in 2009 to a profit of 129.448 MD against a profit of 117.083 MD in 2008.

Our sample consists of eight life insurance companies, In order to measure their performance over a period of 11 years (2005-2015). This choice is justified by the availability of data. Therefore, the financial data were collected from the annual financial statements 
(balance sheet, income statement and statement of cash flows) of the life insurance companies that have been published by them.

\subsection{Model}

In this paper, we use the model who studied the impact of specific variables of a firm (size, leverage, tangibility, risk, premium growth, liquidity and age) on the performance of companies Insurance in Pakistan. We employ the ratio ROA (Return on Asset) as a measure of performance that will be regressed in terms of the explanatory variables.

In this context, the model used in our study is represented as follows:

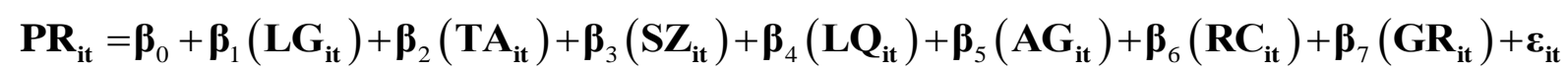
Where:

- $\mathbf{P R}_{\mathbf{i t}}=$ Performance $(\mathrm{ROA})=$ (earnings before interest and taxes divided by total assets).

* $\mathbf{L G}_{\mathbf{i t}}=$ Leverage $($ Leverage $)=$ (total debt / total assets $)$.

- $\mathbf{T A}_{\mathbf{i t}}=$ Tangibility $($ Tangibility $)=($ capital $/$ total assets $)$.

* $\mathbf{S Z}_{\text {it }}=$ Size $($ Size $)=$ Ln (premiums).

* $\mathbf{L Q}_{\mathbf{i t}}=$ Liquidity (Liquidity) $=$ (Current Assets / Current Liabilities).

* $\mathbf{A G}_{\mathbf{i t}}=$ Age (Age) (The difference between the current year and the year of establishment of the company).

- $\mathbf{R C}_{\mathbf{i t}}=$ Risk $($ Risk $)=($ Standard deviation of the ratio of total applications premiums $)$.

* $\mathbf{G R}_{\mathbf{i t}}=($ Growth $)=($ Percent change in premiums $)$.

* $\varepsilon_{\text {it }}=$ The error term.

\section{Empirical results}

\subsection{Descriptive statistics}

In Table 1, we present a descriptive analysis of the different variables associated with insurance companies' life in Tunisia. In fact, in this study, we consider the performance as a dependent variable expressed in terms of specific characteristics of insurance companies such as Tunisian, leverage, size, growth, tangibility, liquidity, risk and age (independent variables).

\section{Table 1.}

Descriptive Statistics

\begin{tabular}{|l|l|l|l|l|l|l|}
\hline Stats & $\mathbf{N}$ & Average & Max & Min & $\begin{array}{l}\text { Standard } \\
\text { deviation }\end{array}$ & Median \\
\hline Leverage & 88 & 0.1687585 & 0.4365028 & 0.0305468 & 0.1033324 & 0.1428552 \\
\hline Tangibility & 88 & 0.6951185 & 0.90702 & 0.4352791 & 0.1279787 & 0.7162244 \\
\hline Size & 88 & 17.57351 & 19.44382 & 14.04266 & 1.457735 & 17.94376 \\
\hline Liquidity & 88 & 4.965466 & 40.99003 & 0.2161963 & 8.514908 & 2.397961 \\
\hline Age & 88 & 33,125 & 60 & 13 & 12.45955 & 33 \\
\hline Risk & 88 & 10.41076 & 35 & 0.2435627 & 9.588427 & 8.432577 \\
\hline
\end{tabular}




\begin{tabular}{|l|l|l|l|l|l|l|}
\hline Growth & 88 & 0.0698127 & 0.4741729 & -0.5520006 & 0.1971104 & 0.0766451 \\
\hline
\end{tabular}

The analysis in Table 1 indicates that the minimum value of the debt ratio (Leverage) is (0.030), while its maximum value is (0.436). Based on the value of the median, we notice that $50 \%$ of Tunisian life insurance companies have an average value $(0.1428)$, which shows us the importance of debt in the activity of these firms.

Thus, we notice that $50 \%$ of life insurance companies have a ratio of Tunisian tangibility (Tangibility) of (0.716) (the median value) so the assets have a large enough value in the composition of the assets of those thereof. During the study period we found that half of the life insurance companies have an average value of the variable size (Size) of (17.94) which is expressed by the natural logarithm of the premiums received by them it from the insured. In addition, we noticed that $50 \%$ of the population in our sample age (Age) 33 years over the study period.

In this context, it fits the importance of age in the business of life insurance companies as may affect the market share and the performance thereof. Indeed, among the life insurance companies in our sample, those with a growth rate (Growth) premiums received is equal to 0.0766. Therefore, changes in premiums may largely influence the profitability of life insurance companies as premiums are the main resources for this type of service business.

Table 2.

Pearson Correlation

\begin{tabular}{|l|l|l|l|l|l|l|l|}
\hline & Leverage & Tangibility & Size & Liquidity & Age & Risk & Growth \\
\hline Leverage & 1 & & & & & & \\
\hline Tangibility & -0.0483 & 1 & & & & & \\
\hline Size & -0.5256 & 0.1183 & 1 & & & & \\
\hline Liquidity & -0.2338 & 0.1914 & -0.0109 & 1 & & & \\
\hline Age & -0.2659 & 0.3293 & 0.3414 & 0.0466 & 1 & & \\
\hline Risk & -0.2036 & 0.4023 & 0.1058 & 0.4541 & 0.1150 & 1 & \\
\hline Growth & -0.1237 & -0.0634 & 0.2042 & -0.3703 & 0.0097 & -0.1539 & 1 \\
\hline
\end{tabular}

In addition, the results show no coefficient exceed the tolerance limit (0.7), which does not cause problems during the regression of performance (ROA). The results for these tests are given in Table 2 .

\subsection{Analysis of the results of the estimation}

After interpreting the results from the table of descriptive and statistical correlation table, we present the results of the estimation of our model that measures the performance of life insurance companies.

First, we present a regression on panel data (double dimension: individual and temporal). In this case, there is a problem in the estimation. That is to say, we will choose between the 
estimate of the fixed effects or random effects by. Our choice is justified by the probability of the Hausman test which must be compared to a value of $10 \%$.

Table 3.

Results of the estimation model for measuring the performance

\begin{tabular}{|c|c|c|c|c|c|}
\hline Pr & Coef & Std. Err. & Student's t & $\mathbf{P}>|\mathbf{t}|$ & [95\% Conf. Interval] \\
\hline Constant & 0.010267 & 1.959826 & 1.54 & 0.137 & {$[-1.02607 ; 7.046603]$} \\
\hline Leverage & -0.1033798 & 0.8500967 & -0.12 & 0.904 & {$[-0.5327734 ; 0.5607563]$} \\
\hline Tangibility & 0.0139914 & 0.2654793 & 0.05 & 0.958 & {$[-0.5419053 ;-0.0136733]$} \\
\hline Size & -0.2777893 & 0.1282404 & -2.17 & $0.040 * *$ & {$[-0.0022039 ; 0.0227791]$} \\
\hline Liquidity & 0.0102876 & 0.0060652 & 1.70 & 0.102 & {$[0.0222604 ; 0.090817]$} \\
\hline Age & 0.0565387 & 0.0166437 & 3.40 & $0.002 *$ & {$[-0.0061138 ; 0.0072396]$} \\
\hline Risk & 0.0005629 & 0.0032418 & 0.17 & 0.864 & {$[0.0625603 ; 0.5070237]$} \\
\hline Growth & 0.284792 & 0.1079036 & 2.64 & $0.014 * *$ & [-1.02607; 7.046603] \\
\hline \multicolumn{6}{|c|}{ Significant at a threshold value $(*) 1 \%,(* *) 5 \%$ and $(* * *) 10 \%$. } \\
\hline \multicolumn{6}{|l|}{$R^{2}=0.6213$} \\
\hline \multicolumn{6}{|c|}{ Adjusted $R^{2}=0.6544$} \\
\hline \multicolumn{6}{|c|}{$F(7.25)=2.79$} \\
\hline \multicolumn{6}{|c|}{$\mathrm{P}>\mathrm{F}=0.0273$} \\
\hline \multicolumn{6}{|c|}{ Hausman test: $\mathrm{P}>$ chi $2=0.0002$} \\
\hline
\end{tabular}

Based on the results shown in Table 3 we note that although the probability of Hausman test is equal to (0.0002). This probability is less than $10 \%$, so we chose the fixed effects model.

In fact, the likelihood is equal to Fisher (0.0273) is less than 5\%. So the estimated model is globally significant.

The value of $\mathrm{R}^{2}$ is (0.6213) indicating that the performance of insurance companies in Tunisia depends almost $62.13 \%$ of independent variables namely, leverage, size, growth, tangibility, age, risk and liquidity.

Therefore, the performance of insurers is defined mainly by these seven variables insurers during the study period. Table 3 indicates that the variable size is inversely proportional to the performance of Tunisian life insurance companies.

The results show that the coefficient on Size (size) is negative $(-0.2777893)$. Thus, this variable is statistically significant negative $(-2.17)$ the $5 \%$ threshold. For this, life insurance Tunisian small size companies are more efficient than those of larger sizes.

The coefficient on age is positive (0.0565387). Thus, this variable has a significant and positive depending on the value of the Student's t which is equal to (3.40) at the $1 \%$ impact. Therefore, the age of an insurance company may affect its performance. This is explained 
through the age of the life insurance companies and their presence on the Tunisian insurance market.

The positive coefficient on the variable Growth (premium growth) indicates positive relationship between growth and yield. Thus, the variable Growth has a positive coefficient (0.284792). This variable is statistically significant positive $(2.64)$ at $1 \%$. Thereafter, the increase in premiums received positively affects the level of performance of insurance companies in Tunisia. In this case, premiums may be an important variable and admits a direct impact on the profitability of insurers.

However, other variables have no influence on the levels of performance of life insurance companies. In this context, the performance of a company, regardless of their type of activity depends on several internal and external factors which are connected with the activity performed by each type of firm.

\section{Conclusion}

This study examines the impact of the characteristics of life insurance Tunisian firms on the level of performance the insurance sector in Tunisia during a period of 11 years (2005-2015). Then, we investigate empirically the effect of firm-specific characteristics (size, leverage, tangibility, risk, growth, liquidity and age) on the profitability of eight Tunisian insurance companies during the period of study from 2005 to 2015 .

The empirical results of the estimation of a regression model on panel data show that three variables, Size (size), age (age) and Growth (growth) are the most important determinants of the performance of the sector of insurance in Tunisia during the period going from 2005 until 2012.

Thus, the two variables Age and Growth have a positive impact on performance while the Size variable has a negative impact on the level of performance. Then, the other variables (Leverage, Tangibility and Liquidity Risk) are insignificant in relation to the performance of life insurance Tunisian firms.

\section{Policy implications}

All the aspects concluded about the empirical analysis are to be taken care for the healthy growth of the insurance industry in Tunisia. If the insurance industry wants to remain 
cost competitive, both life insurers and non-life insurers have to improve their distribution techniques and develop products to change customer behavior.

\section{Suggestions for future research}

For the possible future works, we can add an analysis for the case of non life insurance. Also, we can compare between the two insurance sectors; life and non life.

\section{Acknowledgement}

We would like to thank the editor and anonymous reviewers for their supportive comments and suggestions.

\section{References}

Afanasieff, T., Lhacer, P. and Nakane, M. (2002) 'The determinants of bank interest spread in Brazil', Banco Central di Brazil, Working Papers.

Ahmed, N., Ahmed, Z. and Usman, A. (2011) 'Determinants of Performance: A case of life Insurance Sector of Pakistan', International Research Journal of Finance and Economics, Vol. 128, No. 61, pp. 123-128.

Angbazo, L. (1997) 'Commercial bank net interest margins, default risk, interest-rate risk, and off-balance sheet banking', Journal of Banking and Finance, Vol. 21, pp.5587.

Barajas, A., Steiner, R. and Salazar, N. (1999) 'Interest spreads in banking in Colombia from 1974 to 1996', IMF Staff Papers, Vol. 46, pp.196-224.

Ben Naceur, S. and Goaied, M. (2001) 'The determinants of the Tunisian deposit banks' performance', Applied Financial Economics, Vol. 11, pp. 317-319.

Berger, A. (1995) 'The relationship between capital and earnings in banking', Journal of Money, Credit and Banking, Vol. 27, pp. 404-431.

Chandler, A.D. (1992) 'Organization and performance of enterprises', Published by the organization, Vol. 21.

Demerguç-Kunt, A. and Huizinga, H. (1999) 'Determinants of trading bank interest margins and Profitability: Some international evidence', World Bank Economic Review, Vol. 13, pp. 379-408. 
George, S.A. (2016) 'Productive efficiency, service quality and profitability: a comparative analysis of foreign and private banks in India', International Journal of Productivity and Quality Management (IJPQM), Vol. 18, No. 4, pp. 518-536.

Guru, B.K. and Shanmugam, B. (2002) 'Determinants of Profitability Commercial bank in Malaysia', Multimedia University, Working Papers.

Hakim, S.S. and Neaime, S.S. (2005) 'Profitability and Risk Management in Banking: A Comparative Analysis of Egypt and Lebanon', Research in Middle East Economics, Vol. 6, pp. 117-131.

Horng, M.S., Chang, Y.W. and Wu, T.Y. (2012) 'Does Insurance Demand or Financial Development Promote Economic Growth? Evidence from Taiwan', Applied Economics Letters, Vol. 19, No. 2, pp. 105-111.

Hosseini, M.H. and Saravi-Moghadam, N. (2017) 'A model of customer-based brand equity: evidence from the banking service in Iran', International Journal of Productivity and Quality Management (IJPQM), Vol. 21, No. 1, pp. 23-44.

Kumar, R. and Kumar, V. (2016) 'Operational performance improvement by implementation of value stream mapping - a case study from Indian industry', International Journal of Productivity and Quality Management (IJPQM), Vol. 19, No. 4, pp.526-541.

Lay Hong Tan, L.H., Chew, B.C. and Hamid, S.R. (2016) 'Relationship between service quality and customer satisfaction: a study of Malaysian banking industry', International Journal of Productivity and Quality Management (IJPQM), Vol. 19, No. 1 , pp. $38-50$

Lee, C.C., Lee, C.C. and Chiu, Y.B. (2013) 'The Link between Life Insurance Activities and Economic Growth: Some New Evidences', Journal of International Money and Finance, No. 32, pp. 405-427.

Neely, M.C. and Wheelock, D.C. (1997) 'Why does bank performance vary across states?', Federal Reserve Bank of St. Louis Review, pp. 27-40.

Prakash, A., Mohanty, R.P., Kumar, S. and Kallurkar, S.P. (2011) 'Validation of multipleitem scale for measuring service quality in life insurance business: structural equation modelling approach', International Journal of Productivity and Quality Management (IJPQM), Vol. 8, No. 4, pp.433-458.

Sufian, F. (2009) 'Determinants of bank efficiency falling on unstable macroeconomic environment: Empirical evidence from Malaysia', Research in International Business and Finance, Vol. 23, pp. 54-77. 
Sweis, R.J., Saleh, R.A., Rawan H. Al-Etayyem, R.H., Qasrawi, B.T. and Al Mahmoud, A.M. (2016) 'Total quality management practices and organisational performance in Jordanian courier services', International Journal of Productivity and Quality Management (IJPQM), Vol. 19, No. 2, pp. 258-276.

Taiwo, A. and Olumuyiwa, T.A. (2014) 'Relationship between Insurance and Economic Growth in Sub-Saharan African: A Panel Data Analysis', Modern Economy, No. 5, pp. $120-127$.

Vishal Singh Patyal; Maddulety Koilakuntla, M. (2016) 'Relationship between organisational culture, quality practices and performance: conceptual framework', International Journal of Productivity and Quality Management (IJPQM), Vol. 19, No. 3, pp. 319-344.

Wahjudi, D., Singgih, M.L., Suwignjo, P. and Baihaqi, I. (2016) 'The relationship between organisational culture and firm performance: an empirical study on Indonesian manufacturing firms', International Journal of Productivity and Quality Management (IJPQM), Vol.18, No.1, pp.1-18.

Yinusa, O. and Akino, T. (2013) 'Insurance Development and Economic Growth in Nigeria 1986-2010', Journal of Economics and International Finance, Vol. 5, No. 5, pp. 218-224.

Zhang, Y. and Li, L. (2009) 'Study on Balanced Scorecard of Commercial Bank in Performance Management System', Proceedings of the 2009 International Symposium on Web Information Systems and Applications, Nanchang, PR China, pp. 206-209. 